\title{
Acid, alkali and peroxide pretreatments increase the cellulose accessibility and glucose yield of banana pseudostem
}

\author{
Felipe Lange Shimizu ${ }^{\mathrm{a}}$, Patrícia Queiroz Monteiro ${ }^{\mathrm{b}}$, Pedro Henrique Ciconello Ghiraldi ${ }^{\mathrm{a}}$, \\ Ranieri Bueno Melati ${ }^{\mathrm{a}}$, Fernando Carlos Pagnocca ${ }^{\mathrm{c}}$, Wanderley de Souza ${ }^{\mathrm{d}}$, Celso Sant'Anna ${ }^{\mathrm{b}}$, \\ Michel Brienzo ${ }^{\mathrm{a}, *}$ \\ ${ }^{a}$ Bioenergy Research Institute (IPBEN), Universidade Estadual Paulista (UNESP), Rio Claro, SP, 13500-230, Brazil \\ b Laboratory of Microscopy Applied to Life Science - Lamav, National Institute of Metrology, Quality and Technology - Inmetro, Duque de Caxias, RJ, 25250-020, Brazil \\ ${ }^{\mathrm{c}}$ Center for the Study of Social Insects (CEIS), Universidade Estadual Paulista (UNESP), Rio Claro, SP, 13500-230, Brazil \\ ${ }^{\mathrm{d}}$ Laboratory of Cellular Ultrastructure Hertha Meyer, Federal University of Rio de Janeiro - UFRJ, Rio de Janeiro, RJ, 21949-900, Brazil
}

\section{A R T I C L E I N F O}

\section{Keywords:}

Lignocellulosic biomass

Banana pseudostem

Acid pretreatment

Alkaline pretreatment

Peroxide pretreatment

Glucose yield

Recalcitrance

\begin{abstract}
A B S T R A C T
Lignocellulosic biomasses such as banana pseudostem are attractive cellulose sources for bioenergy production, and for the use in biorefinery processes. However, pretreatment of lignocellulosic material is required to remove hemicellulose and lignin, while increasing cellulose accessibility to enzymatic hydrolysis (i.e., decreasing biomass recalcitrance). The effect of different concentrations of acid $\left(\mathrm{H}_{2} \mathrm{SO}_{4}\right)$, alkaline $(\mathrm{NaOH})$ and peroxide $\left(\mathrm{H}_{2} \mathrm{O}_{2}\right)$ pretreatments on the chemical composition, cellulose accessibility, and enzymatic digestibility of banana pseudostem were studied. The water insoluble solids (WIS) recovery was low $(\sim 30 \%)$ for the severe pretreatment conditions applied, indicating high material solubilization. Acid pretreatment completely removed the hemicellulose content, whereas alkaline and peroxide pretreatments reduced its amount to 4.38 and $8.68 \%$, respectively. In contrast, the lignin content increased (from 17.26 to $39.99 \%$ ) after severe acid pretreatment, while alkaline and peroxide pretreatments reduced the lignin content to $7.65 \%$ and $7.17 \%$, respectively. In line with hemicellulose and lignin removal, the cellulose content increased from 60.84 to 75.48 and $74.37 \%$, respectively for alkaline and peroxide pretreatments, with no alteration for acid. Dye adsorption assays showed that alkaline and acid pretreatments resulted in high internal and external specific surface areas - indicative of high cellulose accessibility - when compared with peroxide pretreatments. Overall, alkaline and acid pretreatments resulted in the highest glucose yields from enzymatic hydrolysis of banana pseudostem, compared with peroxide pretreatment. In conclusion, concentrations of each pretreatment that led to the highest glucose yields was identified, confirming that the banana pseudostem is a great source of fermentable sugars, with high potential for biofuel production.
\end{abstract}

\section{Introduction}

China, the Portuguese Madeira Islands, India and Brazil, among other countries, have large-scale banana production (Li et al., 2010; Cordeiro et al., 2004; Chittibabu et al., 2011; Souza et al., 2012), which generates approximately 4 tons of residue - in the form of unused banana pseudostem - per ton of harvested fruit (Souza et al., 2010). Therefore, banana pseudostem and fruit-bunch stem are available in large scale in numerous tropical and subtropical countries, and represent a major income source in some communities/countries (Cordeiro et al., 2004). Due to its high cellulose content, the pseudostem from some banana species has been used in paper making and in the pulping industry since the 60's (Guha, 1960), and the cellulose of banana biomass waste has potential for use in the production of sodium carboxymethyl cellulose (Adinugraha and Marseno, 2005) and polyphenol oxidase (Wuyts et al., 2006).

Banana pseudostem residue may also have industrial applications, as feedstock for high-value products such as biofuels, which could replace non-renewable fuel sources, to mitigate the ever-growing $\mathrm{CO}_{2}$ emissions (Quintero et al., 2008). While the use of banana pseudostem for second-generation (2G) ethanol production (bioethanol) is particularly attractive, this residue is difficult to convert into bioethanol or other high-value molecules, due to its chemical composition and physicochemical properties. While the pseudostem from banana species such as Musa cavendishii have higher cellulose content than grasses and wheat straw (44\% of cellulose and only $8 \%$ of lignin in dry mass; Souza

\footnotetext{
* Corresponding author.

E-mail address: mbrienzo@ipben.unesp.br (M. Brienzo).
} 
Table 1

Solid recovery and chemical composition of untreated and pretreated banana pseudostem.

\begin{tabular}{|c|c|c|c|c|c|}
\hline \multirow[b]{2}{*}{ Pretreatment condition $(\% \mathrm{~m} / \mathrm{m})$} & & \multicolumn{3}{|c|}{ Composition (\% dry base) } & \multirow{2}{*}{$\begin{array}{l}\text { Water-insoluble solids } \\
\text { (WIS) (\%) }\end{array}$} \\
\hline & & Glucan/Cellulose & Hemicellulose & Lignin & \\
\hline & Untreated & $60.84 \pm 1.34$ & $19.62 \pm 0.53$ & $17.26 \pm 0.31$ & - \\
\hline \multirow[t]{8}{*}{$\mathrm{H}_{2} \mathrm{SO}_{4}$} & 5 & $59.68 \pm 1.14$ & $12.57 \pm 0.53$ & $26.28 \pm 0.37$ & $60.57 \pm 1.59$ \\
\hline & 10 & $61.62 \pm 1.26$ & $11.66 \pm 1.99$ & $25.66 \pm 2.06$ & $58.20 \pm 2.01$ \\
\hline & 15 & $63.76 \pm 1.23$ & $8.29 \pm 2.45$ & $29.16 \pm 1.54$ & $53.30 \pm 1.95$ \\
\hline & 20 & $63.37 \pm 1.71$ & $4.13 \pm 0.10$ & $30.08 \pm 0.63$ & $46.90 \pm 1.05$ \\
\hline & 25 & $66.28 \pm 0.68$ & $3.97 \pm 0.50$ & $31.15 \pm 2.99$ & $44.90 \pm 1.56$ \\
\hline & 30 & $65.11 \pm 1.68$ & - & $36.22 \pm 1.15$ & $30.30 \pm 0.98$ \\
\hline & 35 & $62.26 \pm 0.89$ & - & $36.47 \pm 2.07$ & $31.20 \pm 1.09$ \\
\hline & 40 & $60.76 \pm 1.32$ & - & $39.99 \pm 2.35$ & $32.10 \pm 2.05$ \\
\hline \multirow[t]{6}{*}{$\mathrm{NaOH}$} & 5 & $59.65 \pm 2.76$ & $14.02 \pm 1.02$ & $17.11 \pm 2.36$ & $46.00 \pm 2.25$ \\
\hline & 10 & $64.32 \pm 1.59$ & $12.31 \pm 0.49$ & $13.10 \pm 1.18$ & $43.50 \pm 2.19$ \\
\hline & 15 & $61.63 \pm 3.94$ & $11.47 \pm 1.05$ & $11.09 \pm 1.08$ & $33.80 \pm 1.97$ \\
\hline & 20 & $70.01 \pm 3.83$ & $9.68 \pm 2.55$ & $10.78 \pm 1.67$ & $29.20 \pm 2.13$ \\
\hline & 25 & $76.52 \pm 1.61$ & $5.35 \pm 0.56$ & $6.24 \pm 0.83$ & $27.60 \pm 1.75$ \\
\hline & 30 & $75.48 \pm 1.89$ & $4.38 \pm 0.36$ & $7.65 \pm 0.97$ & $25.00 \pm 1.14$ \\
\hline \multirow[t]{4}{*}{$\mathrm{H}_{2} \mathrm{O}_{2}$} & 2 & $61.77 \pm 3.02$ & $15.93 \pm 1.03$ & $14.19 \pm 2.17$ & $48.60 \pm 2.30$ \\
\hline & 4 & $66.91 \pm 2.39$ & $14.17 \pm 1.68$ & $10.49 \pm 0.70$ & $42.70 \pm 1.39$ \\
\hline & 6 & $70.99 \pm 1.99$ & $11.31 \pm 1.54$ & $9.29 \pm 1.24$ & $39.90 \pm 1.89$ \\
\hline & 8 & $74.37 \pm 2.57$ & $8.68 \pm 0.77$ & $7.17 \pm 0.48$ & $32.40 \pm 2.21$ \\
\hline
\end{tabular}

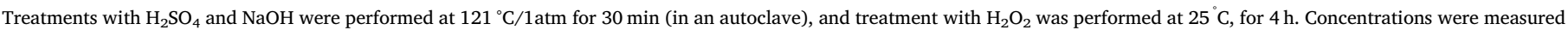

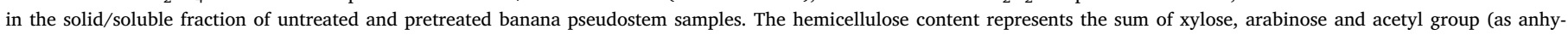

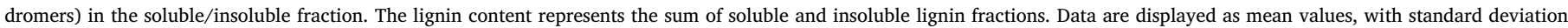
values in parentheses (experiments were performed in triplicates). (-) not detected.

et al., 2012), representing a rich source of cellulose, the lignocellulosic nature of the banana pseudostem means that its cellulose fraction is not easily accessible to the enzyme digestion required for ethanol production.

The inherent resistance of lignocellulosic material to enzymatic digestion, termed biomass 'recalcitrance', can be overcome by pretreatments that remove or modify lignin, leaving cellulose more accessible to enzymes (Sant'Anna et al., 2014; Meng et al., 2013; Brienzo et al., 2017). Pretreatments disrupt the biomass structure, to enhance the effectiveness of enzymatic hydrolysis (Meng et al., 2013). The most commonly used pretreatment to remove hemicelluloses is the exposure of biomass to alkaline $(\mathrm{NaOH})$ or acid $\left(\mathrm{H}_{2} \mathrm{SO}_{4}\right)$ solutions ( $\mathrm{Hu}$ and Wen, 2008; Idrees et al., 2013; Souza et al., 2012). Also, previous studies from our group showed that peroxidase pretreatment of lignocellulosic materials (sugarcane bagasse) removes lignin efficiently, producing reusable solubilized hemicellulose (Brienzo et al., 2009; Monte et al., 2010). The results reported by Souza and co-workers (2012) indicate that is possible to produce approximately $187 \mathrm{~L}$ of ethanol for each ton of banana pseudostem using a low severity acid pretreatment. However, the effects of pretreatment on the banana pseudostem have not been analyzed systematically, to identify the ideal pretreatment conditions for maximal glucose yield from this biomass source.

Given the abundance of banana pseudostem as raw material, and the importance of using lignocellulosic waste for $2 \mathrm{G}$ ethanol production, the effect of $\mathrm{NaOH}, \mathrm{H}_{2} \mathrm{SO}_{4}$ and $\mathrm{H}_{2} \mathrm{O}_{2}$ pretreatments on the banana pseudostem were studied. As well as comparing the chemical characteristics of pretreated and untreated samples, the exposure of inner and outer surfaces of cellulose using dye adsorption were studied (Direct Orange and Direct Blue), and visualized directly the changes in surface morphology induced by pretreatments, using scanning electron microscopy (SEM). Finally, it was assessed whether pretreatments improved the susceptibility of banana pseudostem to enzymatic hydrolysis, raising the glucose yield to levels compatible with efficient biofuel production.

\section{Methodology}

\subsection{Banana pseudostem}

Banana pseudostems were collected from mature plants at a local area in Duque de Caxias (Rio de Janeiro, RJ, Brazil). After collection, pseudostems were sliced and dried under sunlight for four days, cut into small pieces, ground by knife mill and selected using 20-mesh sieves. Dried and milled samples were stored at room temperature, in plastic bags.

\subsection{Alkaline pretreatment}

For alkaline pretreatment, $5 \mathrm{~g}$ of dried and milled samples were transferred to $100 \mathrm{~mL}$ glass bottles and mixed with solutions of 5,10 , $15,20,25$ or $30 \% \mathrm{NaOH}(\mathrm{m} / \mathrm{m})$ in a total reaction volume of $50 \mathrm{~mL}$. After homogenization, samples were autoclaved at $121^{\circ} \mathrm{C} / 1 \mathrm{~atm}$ for $30 \mathrm{~min}$, allowed to cool down at room temperature, and the soluble and solid (insoluble) fractions were separated by filtration using a paper filter. The solid fraction was washed with deionized water to reach $\mathrm{pH}$ 7 , dried in an oven at $45^{\circ} \mathrm{C}$ and stored in plastic bags until further analysis (Brienzo et al., 2016). Pretreatments were performed in duplicates and the solid recovery average was shown.

\subsection{Acid pretreatment}

Acid pretreatment was performed by adding $5 \mathrm{~g}$ of dried and milled samples to $250 \mathrm{~mL}$ glass bottles containing $100 \mathrm{~mL}$ of $5,10,15,20,25$, 30,35 or $40 \% \mathrm{H}_{2} \mathrm{SO}_{4}(\mathrm{~m} / \mathrm{m})$. Samples were autoclaved at $121{ }^{\circ} \mathrm{C} / 1 \mathrm{~atm}$ for $30 \mathrm{~min}$, allowed to cool down at room temperature and vacuum filtered. The solid fraction was washed with deionized water to reach pH 5 (Brienzo et al., 2014), dried at $45^{\circ} \mathrm{C}$ in an oven and stored in plastic bags until further analysis. Pretreatments were performed in duplicates and the solid recovery average was shown.

\subsection{Peroxide pretreatment}

Peroxide pretreatment was performed by adding $\sim 5 \mathrm{~g}$ of dried and milled samples to $250 \mathrm{~mL}$ bottles containing $100 \mathrm{~mL}$ of $2,4,6$ or $8 \%$ 


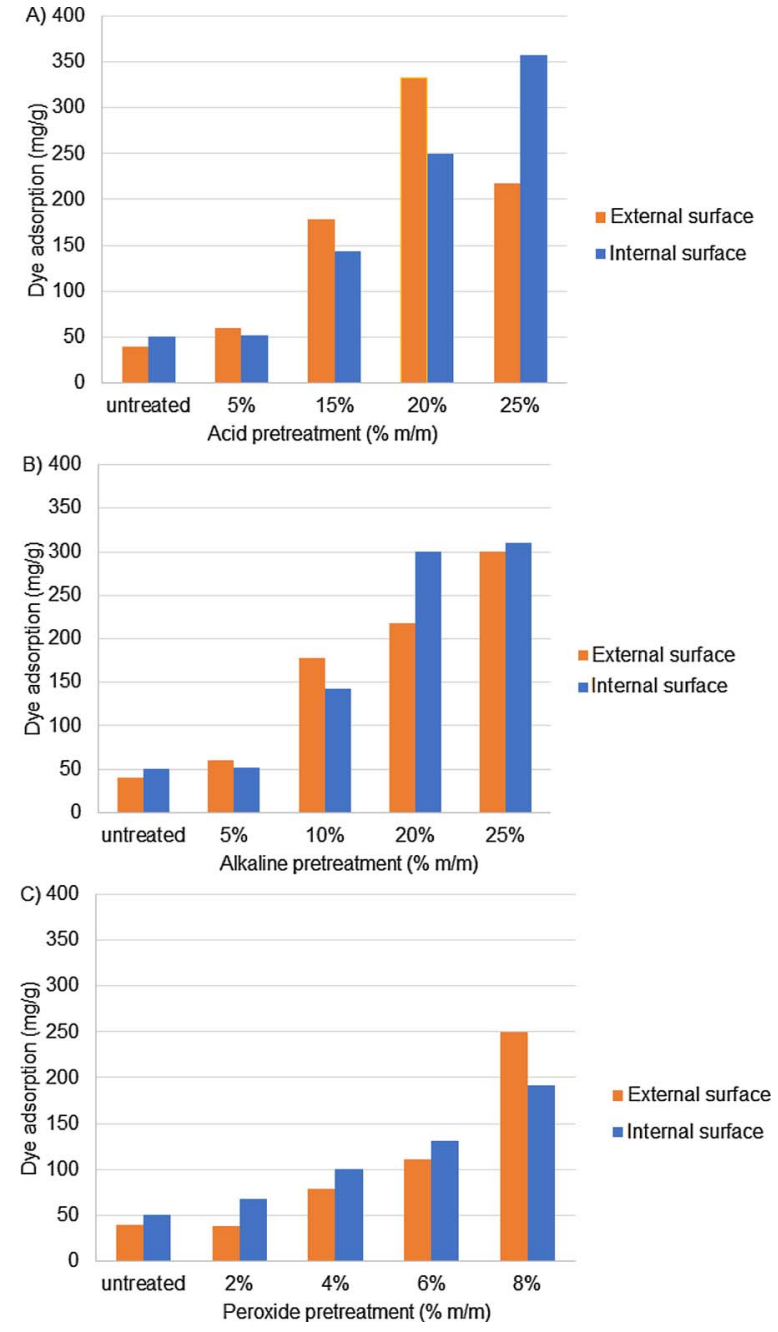

Fig. 1. Direct Orange (external specific surface area, in orange) and Direct Blue (internal specific surface area, in blue) dye adsorption analysis of banana pseudostem left untreated or pretreated with sulfuric acid $\left(\mathrm{H}_{2} \mathrm{SO}_{4}, \mathrm{~A}\right)$, sodium hydroxide $(\mathrm{NaOH}, \mathrm{B})$ or hydrogen peroxide $\left(\mathrm{H}_{2} \mathrm{O}_{2}, \mathrm{C}\right.$ ). (For interpretation of the references to colour in this figure legend, the reader is referred to the web version of this article.)

$\mathrm{H}_{2} \mathrm{O}_{2}(\mathrm{~m} / \mathrm{m})$. After homogenization, samples were heated in a thermostatic water bath at $25^{\circ} \mathrm{C}$ for $4 \mathrm{~h}$, and the soluble and insoluble (solid) fractions were separated by filtration using a paper filter. The solid fraction was washed with deionized water until neutral $\mathrm{pH}$ was reached (Monte et al., 2010), dried at $45^{\circ} \mathrm{C}$ in an oven and stored in plastic bags until further analysis. Pretreatments were performed in duplicates and the solid recovery average was shown.

\subsection{Chemical characterization}

The chemical composition of untreated and pretreated samples was determined according to the National Renewable Laboratory Analytical Procedure (NREL, USA) (Sluiter et al., 2010). The concentrations of the monomeric sugars glucose, arabinose and xylose in the soluble fraction were determined by HPLC using a BIORAD HPX87H column, eluted at $0.6 \mathrm{~mL} / \mathrm{min}$ with $5 \mathrm{mM}$ sulfuric acid, at $60^{\circ} \mathrm{C}$. Mannose and galactose peaks overlapped and, thus, these sugars were not quantified. The following monomer-to-anhydromonomer conversion factors were used: 0.90 for glucose, 0.88 for arabinose and xylose, and 0.72 for acetyl content. After correction by a hydration factor, the glucose content was reported as glucan (total glucose), and the contents of other sugars added to that of acetic acid were used to calculate the hemicellulose content. Lignin was reported as the sum of insoluble (gravimetrically determined) and soluble (determined by spectrophotometry at $240 \mathrm{~nm}$ ) lignin.

\subsection{Dye adsorption}

The dye adsorption of pretreated solid samples was measured by an adaptation of the Simons' staining method (Chandra et al., 2008). First, $50 \mathrm{mg}$ of dry pretreated samples were placed in six $15 \mathrm{~mL}$ centrifuge tubes containing $0.5 \mathrm{~mL}$ phosphate buffered saline solution (PBS, $\mathrm{pH}$ 6, $0.3 \mathrm{M} \mathrm{PO}_{4}, 1.4 \mathrm{mM} \mathrm{NaCl}$ ). The amount of dye adsorbed onto each sample was determined by the difference between the initial and final dye concentrations in the supernatant. The Direct Orange (DO) and Direct Blue (DB) dye concentrations were determined using the following formulas (Eqs. (1) and (2), respectively):

$\mathrm{A}_{455 \mathrm{~nm}}=\mathrm{E}_{\mathrm{O} / 455} \mathrm{LC}_{\mathrm{O}}+\mathrm{E}_{\mathrm{B} / 455} \mathrm{LC}_{\mathrm{B}}$

$\mathrm{A}_{624 \mathrm{~nm}}=\mathrm{E}_{\mathrm{O} / 624} \mathrm{LC}_{\mathrm{O}}+\mathrm{E}_{\mathrm{B} / 624} \mathrm{LC}_{\mathrm{B}}$

Where $A$ is the adsorption of the mixture at 450 or $624 \mathrm{~nm}$, E is the extinction coefficient of each component at the respective wavelength, and $\mathrm{L}$ is the path length (width of the cuvette, $1 \mathrm{~cm}$ ). The extinction coefficients were calculated using standard curves for each dye. The values calculated and used in this study were as follows: $\mathrm{EO} / 455=25$; $\mathrm{EB} / 455=0.9 ; \mathrm{EO} / 624=3.2 ;$ and $\mathrm{EB} / 624=15.5 \mathrm{~L} \mathrm{~g}^{-1} \mathrm{~cm}^{-1}$.

\subsection{Enzymatic hydrolysis}

Pretreated and untreated samples $(0.1 \mathrm{~g})$ were digested in $15 \mathrm{~mL}$ flasks containing $5 \mathrm{~mL}$ of $0.05 \mathrm{M}$ citrate buffer ( $\mathrm{pH} 4.8$ ) supplemented with $15 \mathrm{FPU} / \mathrm{g}$ cellulase (Celluclast $1.5 \mathrm{~L}$, Novozymes) and $15 \mathrm{U} / \mathrm{g}$ cellobiase ( $\beta$-glucosidase; Novozyme 188 ), to provide enough enzymatic activity and prevent product inhibition, respectively. Reactions were incubated for $3-72 \mathrm{~h}$ at $50^{\circ} \mathrm{C}$, in an orbital shaker at $170 \mathrm{rpm}$. The glucose yield (determined by HPLC) was calculated from samples taken at different reaction times (3, 6, 9, 16, 24, 48 and $72 \mathrm{~h}$ ). Enzymatic hydrolysis assays were performed in experimental duplicates, and averaged results were reported. The glucan conversion was calculated according to Eq. (3):

Glucan conversion $(\%)=[($ glucose $)+1.053 *($ cellobiose $)] /$ $[1.111 * f *$ (biomass) $] * 100$

Where:[Glucose] Concentration of glucose released during enzymatic hydrolysis (g/L)[Cellobiose] Concentration of cellobiose released during enzymatic hydrolysis ( $\mathrm{g} / \mathrm{L}$ ) [Biomass] Dry biomass concentration at the beginning of the enzymatic hydrolysis $(\mathrm{g} / \mathrm{L}) \mathrm{f}$ Glucan fraction in dry biomass $(\mathrm{g} / \mathrm{g}) 1.053$ Correction factor of cellobiose to glucose equivalents1.111 Conversion factor of glucan to glucose equivalents

\subsection{Scanning electron microscopy (SEM)}

For SEM analysis, untreated and pretreated banana pseudostem samples were washed with deionized water and dried at $45^{\circ} \mathrm{C}$ for $24 \mathrm{~h}$. Samples were mounted onto stubs using carbon double-sided tape, coated with $5 \mathrm{~nm}$ platinum, and examined in a FEI Quanta FEG 450 scanning electron microscope, operating at an accelerating voltage of $1 \mathrm{kV}$.

\section{Results}

3.1. Severe alkaline and peroxide pretreatments are more efficient than severe acid pretreatment at increasing the cellulose content of banana pseudostem

Banana pseudostem is an abundant agricultural waste product with potential as a raw material for biofuel production, due to its high cellulose content. It was examined the effects of different pretreatments 


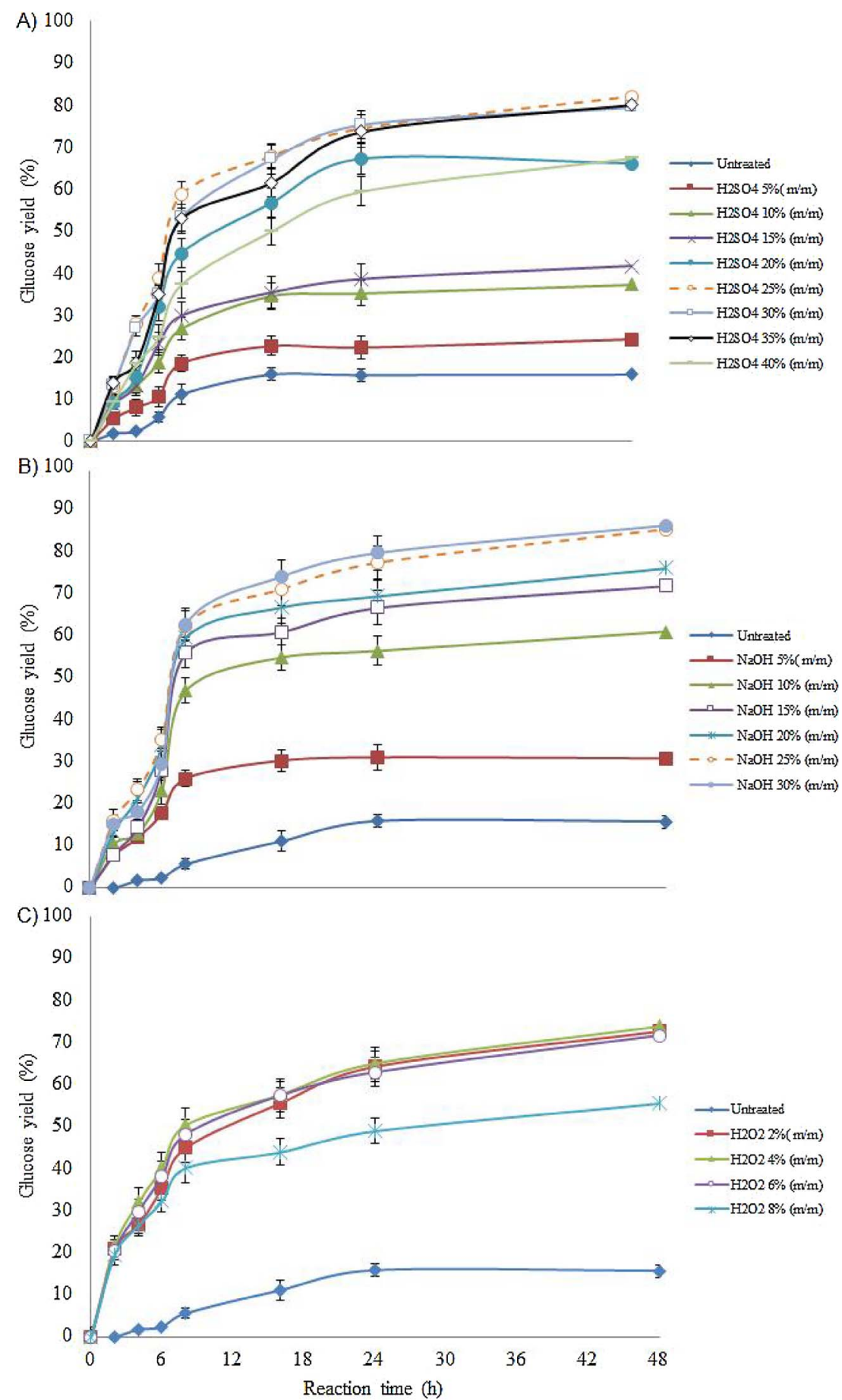

Fig. 2. Glucose yield from enzymatic hydrolysis of banana pseudostem samples left untreated, or pretreated with acid (A), alkali (B) or peroxide (C).

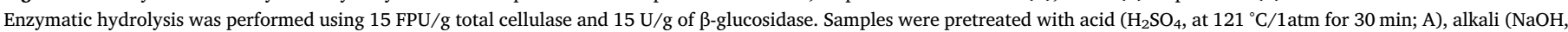
at $121^{\circ} \mathrm{C} / 1 \mathrm{~atm}$ for $30 \mathrm{~min}$; B) or peroxide $\left(\mathrm{H}_{2} \mathrm{O}_{2}\right.$, at $25^{\circ} \mathrm{C}$ for $\left.4 \mathrm{~h} ; \mathrm{C}\right)$.

capable of making the cellulose content of banana pseudostem accessible for enzymatic digestion, with a view at using the pseudostem in $2 \mathrm{G}$ ethanol production, and in the generation of other high-value molecules.

Pretreatment decreases the recalcitrance of lignocellulosic material, by removing lignin and hemicellulose, thereby exposing cellulose to enzyme action (Meng et al., 2013; Brienzo et al., 2017). The residual pseudostem of banana cultivation was subjected to different pretreatments, including acid pretreatment, which preferentially removes hemicellulose (Souza et al., 2012), and both peroxide and alkaline pretreatments, which remove lignin and hemicellulose (Hu and Wen,
2008; Brienzo et al., 2009). Then, it was evaluated the chemical and physicochemical changes on the biomass exerted by each pretreatment condition, and their effect cellulose enzymatic hydrolysis.

Severe pretreatment conditions $\left(\geq 25 \% \mathrm{H}_{2} \mathrm{SO}_{4}, \geq 20 \% \mathrm{NaOH}\right.$ and $8 \% \mathrm{H}_{2} \mathrm{O}_{2}$ ) effectively removed biomass components (Table 1 ), and resulted in lower water-insoluble solids (WIS) recovery than lower severity conditions ( $5 \%$ acid, $5 \%$ alkaline and $2 \%$ of peroxide) (Table 1 ). The solid recovery values observed for pseudostem were lower than those reported for other lignocellulosic materials, such as sugarcane fractions (Brienzo et al., 2014), bagasse (Benjamin et al., 2013) and wood residues (Cavalaglio et al., 2016)., Depending on the 

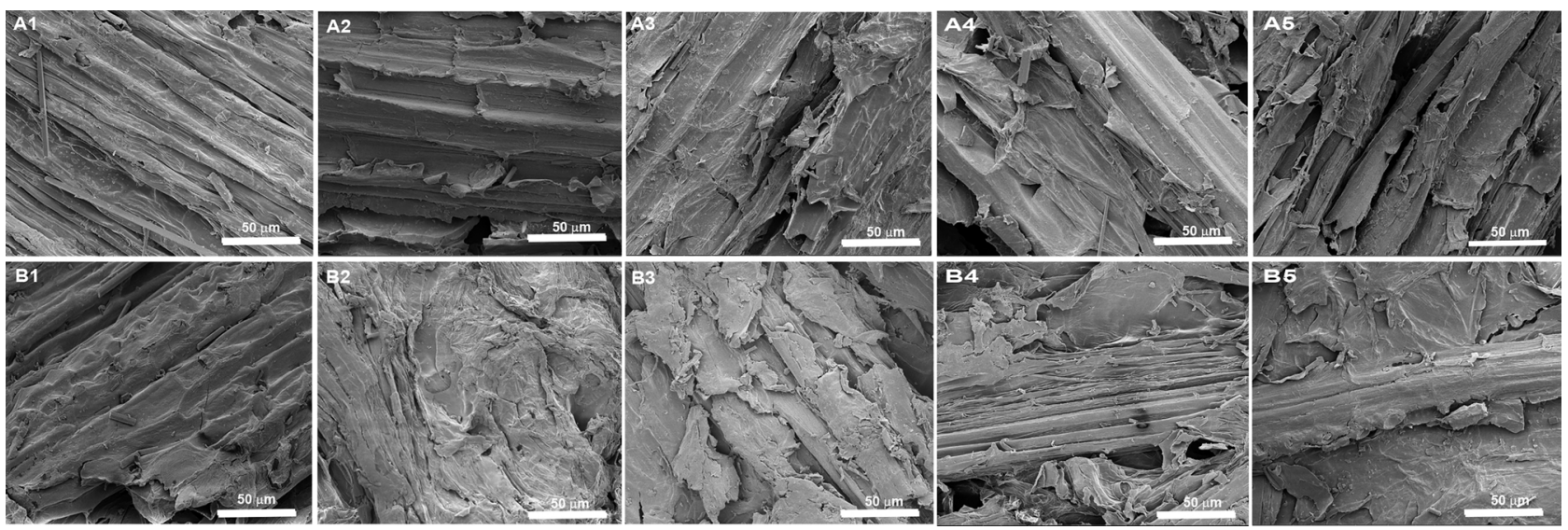

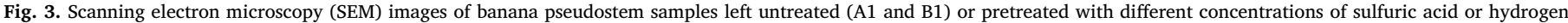
peroxide.

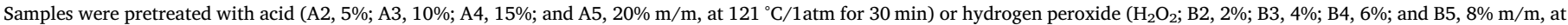
$25^{\circ} \mathrm{C}$ for $\left.4 \mathrm{~h}\right)$.

pretreatment type and condition, the removal of hemicellulose and lignin contributed to mass solubilization and to the low WIS recovery. Moreover, the banana pseudostem extractives, which correspond to $\sim 10 \%$ of the total mass (Cordeiro et al., 2004), are solubilized, contributing to decrease the WIS.

The chemical characterization of the untreated pseudostem showed that this fraction is composed of $60.84 \%$ glucan (representing the cellulose fraction), $19.62 \%$ hemicellulose, $19.26 \%$ lignin, and $10.5 \%$ extractives (Table 1). Previous studies reported similar values, of $64.58 \%$ glucan, $24.84 \%$ hemicellulose, and $10.78 \%$ lignin (Li et al., 2010), and $66.6 \%$ glucan (of which $13 \%$ were ashes and $14.1 \%$ were extractives) (Cordeiro et al., 2004) for banana pseudostem. The chemical characterization reported in this study confirms the high glucan content of the banana pseudostem, reinforcing the notion that this residue represents a good source of fermentable sugars (Li et al., 2010; Idrees et al., 2013), with potential for the production of ethanol after pretreatment (Souza et al., 2012). Moreover, the low lignin content observed in this and in other studies indicates that the banana pseudostem is likely to be less recalcitrant than other lignocellulosic materials.

The mass loss (represented by low WIS recovery) observed after pretreatment with high catalyst concentrations (25.0-32.10\%; Table 1) can be attributed to the depolymerization of carbohydrates/hemicellulose and to the solubilization of extractives (Brienzo et al., 2014). Acid pretreatment breaks glycosidic bonds randomly, removing hemicellulose while increasing the cellulose content of biomass (Brienzo et al., 2017), and improving the accessibility of cellulose to hydrolytic enzymes (Brienzo et al., 2017; Meng et al., 2013; Chandra et al., 2008). On the other hand, alkaline pretreatment causes nucleophilic attacks that break the lignin structure, solubilizing lignin fragments or hemicellulose from $\alpha-O-4$ linkages (Fengel and Wegener, 1984). Similarly to alkaline pretreatment, peroxide pretreatment contributes to lignin structure breakdown.

Under the most extreme conditions used (i.e., at the highest concentrations of catalysts), hemicellulose was completely removed upon acid pretreatment, and its percentage decreased to approximately 4.38 and $8.68 \%$ under the most severe alkaline and peroxide pretreatments, respectively, compared with $19.62 \%$ in the untreated control (Table 1).

Acid pretreatment led to an increase in the glucan and lignin content, as result of hemicellulose removal (Table 1). However, the increase in the percentage of cellulose was observed at acid concentration up to $25 \%$, which led to contents of $66.28 \%$ of glucan, $3.97 \%$ of hemicellulose, and $31.15 \%$ of lignin. However, the glucan content decreased to $60.76 \%$, (compared with $66.28 \%$ after pretreatment with $25 \%$ acid) under higher acid concentrations (40\%), despite the complete removal of hemicellulose (Table 1). These results suggest that the most aggressive acidic conditions used caused significant cellulose degradation, resulting in a decrease in the cellulose content of the banana pseudostem biomass and, therefore, leaving less substrate for enzymatic hydrolysis. Severe alkaline and peroxide pretreatments increased the glucan content by a further 10 percentage points (to $76.52 \%$ and $74.37 \%$, after pretreatment with $25 \% \mathrm{NaOH}$ and $8 \% \mathrm{H}_{2} \mathrm{O}_{2}$, respectively) compared with $25 \%$ acid, despite incomplete hemicellulose removal $(5.35 \%$ and $8.68 \%$, respectively). Therefore, severe alkaline $(25 \%)$ and peroxide $(8 \%)$ pretreatments were more efficient at increasing the glucan content in banana pseudostem biomass than severe acid pretreatment (at 25\%), with efficient removal of both hemicellulose and lignin.

While lower alkaline conditions (5 and 15\%) resulted in little chemical composition modification, treatment with the highest concentration of $\mathrm{NaOH}(30 \%)$ decreased slightly the cellulose content of the biomass (to $75.48 \%$ ), relative to $25 \% \mathrm{NaOH}$ (Table 1), suggesting that a small amount of cellulose degradation occurred in the most extreme alkaline conditions tested, similarly to that observed in the most extreme acid conditions. The aggressive conditions of alkali pretreatment possibly removed hemicellulose and lignin to an extent that cleaved hydrogen bonds in amorphous regions of the cellulose molecules. This effect is expected to increase the crystalline cellulose fraction, which has higher recalcitrance compared with the amorphous fraction (Fig. 1C). Notably, severe acid pretreatment did not remove efficiently the lignin content from the biomass, with an increase in the lignin content from $17.26 \%$ (in the untreated) to $39.99 \%$ after $40 \%$ acid pretreatment. In comparison, severe alkaline and peroxide treatments reduced the lignin content to $\sim 7 \%$ (Table 1 ).

\subsection{Pretreatments with acid and alkali increase cellulose accessibility}

The removal of biomass components such as hemicellulose and lignin increases cellulose accessibility to enzymatic digestion (Brienzo et al., 2017, 2015; Meng et al., 2013; Sant'Anna et al., 2014). To evaluate cellulose accessibility after treatment, the internal and external specific surface areas of banana pseudostem samples were estimated, using blue and orange dye adsorption, respectively (Chandra et al., 2008). Increases in dye adsorption represent increases in cellulose accessibility, due to a direct relationship between the alpha-cellulose content of the biomass and the glucose yield from enzymatic hydrolysis (Brienzo et al., 2015, 2017).

Both the external and the internal surface areas of banana pseudostem samples increased after pretreatment, compared with untreated samples (Fig. 1), in line with the removal of hemicellulose and lignin after treatment (Table 1), which exposes cellulose areas to dye 
adsorption. Lower severity pretreatments led to limited increases in the internal and external surface areas (with predominant increases in the external surface area) compared with untreated samples (Fig. 1). The external and internal specific surface areas increased gradually with pretreatment severity, with the exception of $25 \%$ acid pretreatment, which decreased the external surface area, relative to pretreatment with $20 \%$ acid (Fig. 1A). Pretreatment with acid and alkali resulted in higher levels of dye adsorption than peroxide pretreatment (Fig. 1A and B), and treatment with up to $6 \%$ peroxide increased the internal surface area predominantly, while the use of $8 \%$ peroxide resulted in a higher external surface area than the internal surface area (Fig. 1C).

For the same amount of lignin removal and glucan content increase, severe peroxide pretreatment (8\%) was less efficient than severe alkali pretreatment (30\%) at removing hemicellulose from the banana pseudostem biomass (Table 1), which may explain the limited increase in cellulose accessibility after peroxide treatment (Fig. 1C). This pretreatment may have affected the physicochemical properties of the banana pseudostem biomass in a manner that reduced the accessibility of cellulose molecules. The lower temperature used in peroxide pretreatment, compared with that used in alkaline and acid pretreatments (Brienzo et al., 2017), and the increased/decreased swelling of the biomass observed after peroxide treatment (Junior et al., 2013) might explain the increased accessibility obtained after pretreatment with $\mathrm{NaOH}$ or $\mathrm{H}_{2} \mathrm{SO}_{4}$.

\subsection{Acid and alkaline pretreatments are more efficient than peroxide pretreatment at increasing the glucose yield from banana pseudostem}

Enzymatic hydrolysis of untreated banana pseudostem resulted in $15.9 \%$ glucose yield after $48 \mathrm{~h}$ of reaction, which is lower than the yield obtained with other untreated lignocellulosic materials such as sugarcane bagasse (Corrales et al., 2012; Brienzo et al., 2015). All pretreatments improved the enzymatic hydrolysis yield of banana pseudostem (Fig. 2), in agreement with the chemical composition and dye adsorption data showing that all pretreatments removed hemicellulose from the biomass (Table 1) and increased cellulose accessibility (Fig. 1).

Lignin and hemicellulose removal from lignocellulosic materials as a result of pretreatment - probably creates pores in the biomass that allow the entry of cellulolytic enzymes, which hydrolyze cellulose into glucose. This effect is especially potent when the lignin content is less than 10\% (Mooney et al., 1998), which was obtained in the present study using strong alkali or peroxide concentrations. Severe pretreatments increased the glucose yield by $4.6-5.3$ fold, and the material pretreated with $25 \%$ alkali showed the highest glucose yield (85\%) after enzymatic hydrolysis, followed by $25 \%$ acid pretreatment $(82 \%$ glucose yield), whereas $4 \%$ peroxide pretreatment had the lowest glucose yield (74\%) of all pretreated conditions (Fig. 2).

The enzymatic hydrolysis data show that the use of appropriate concentrations of acid or alkali during pretreatment leads to higher glucose yields for banana pseudostem samples, compared with untreated samples (Fig. 2). While the glucose yield increased progressively with increasing concentrations of $\mathrm{NaOH}$, the most extreme condition of acid pretreatment $(40 \%)$ used resulted in a lower glucose yield $(60 \%)$ compared with moderate acid concentrations (20\%), which resulted in $82 \%$ yield (Fig. 2). Extreme acidity may generate a more recalcitrant biomass, by degrading preferentially the amorphous fraction of cellulose, thereby increasing the proportion of the more recalcitrant crystalline fraction in the biomass. This high severity acid pretreatment condition is not commonly used. Pretreatment with such extreme acidity had not been reported previously for banana pseudostem samples, and our study indicates that extreme acidity is not an ideal pretreatment for this particular biomass type.

While lignin removal increases the glucose yield from enzymatic hydrolysis (Siqueira et al., 2011), the magnitude of this effect may vary depending on the initial lignin content in the raw material (Benjamin et al., 2013), on the distribution of lignin in different biomass fractions
(Brienzo et al., 2016), and on the physicochemical properties of the biomass (Zhu et al., 2008; Brienzo et al., 2017). The lignin content was similar after strong alkaline and peroxide pretreatments (7.65 and 7.17, respectively; Table 1); however, the glucose yield was higher for the alkaline pretreated material (Fig. 2), in agreement with the higher glucose accessibility in these samples (Fig. 1). Pretreatment with peroxide did not have a concentration-dependent effect on the glucose yield, with 2-6\% peroxide pretreatments leading to similar increases in the glucose yield (relative to the untreated), while pretreatment with $8 \%$ peroxide reduced the glucose yield compared with moderate peroxide pretreatment (Fig. 2C). Higher peroxide pretreatment is likely to have attacked mainly the amorphous cellulose fraction, resulting in a more recalcitrant substrate.

\subsection{Effective pretreatments alter the surface of banana pseudostem samples}

Scanning electron microscopy (SEM) analysis was used to evaluate the changes in the cell wall surface morphology in pretreated banana pseudostem samples. The SEM analysis was performed with 5-20\% acid pretreated samples, because these conditions removed hemicellulose effectively, and with $2-8 \%$ peroxide pretreated samples, because these conditions removed both hemicellulose and lignin effectively. On the other hand, peroxide pretreated samples resulted in lower accessibility and glucose yield by enzymatic hydrolysis than acid pretreated. Untreated banana pseudostem had a smooth surface with an undamaged fibrous organization (Fig. 3A1, B1), which appeared only slightly modified by pretreatment with a low concentration (5\%) of acid (Fig. 3A2). However, alterations in the material surface morphology with increased acid pretreatment severity were observed (Fig. 3). Exposure to $10 \%$ acid led to a disorganization of the surface of material (Fig. 3A3, A4 and A5), which was already apparent after $2 \%$ peroxide pretreatment (Fig. 3B2). When samples were pretreated with a higher concentration of peroxide (6-8\%), a stronger morphological change was observed, compared with untreated samples (Fig. 3B3, B4 and B5). The removal of biomass components, such as hemicellulose and lignin, by the peroxide pretreatment resulted in morphological surface modification of banana pseudostem samples. Damaged surfaces were no longer smooth, showing danification and were clearly fragmented in appearance. In line with the complete hemicellulose removal by strong (30\%) acid pretreatment (Table 1), this pretreatment also altered the morphology of banana pseudostem surfaces (Fig. 3).

Pretreatments that resulted in a high $(\geq 65 \%)$ glucose yield from enzymatic hydrolysis - such as $20 \%$ acid and $2-6 \%$ peroxide (Fig. 2) also damaged the banana pseudostem surface considerably (Fig. 3). Interestingly, the surface damage observed by SEM was similar for $2 \%$ peroxide pretreated samples, which had lower dye accessibility (Fig. 1C), and for $20 \%$ acid pretreated material, which had considerably higher dye accessibility than $2 \%$ peroxide (Fig. 1A).

\section{Conclusion}

A detailed evaluation of the effects of different pretreatments on the banana pseudostem showed that all severe pretreatments resulted in low solid recovery, in agreement with the high amount of hemicellulose and lignin removal from these samples. Acid pretreatment was particularly effective at removing hemicellulose, while alkaline and peroxide pretreatments removed both hemicellulose and lignin effectively. The removal of biomass components exposed cellulose, increasing its accessibility and, consequently, the glucose yield from enzymatic hydrolysis. However, the most severe pretreatments with acid and peroxide resulted in cellulose degradation, increasing biomass recalcitrance relative to lower severity conditions (possibly due to a reduction in the amorphous cellulose fraction). The banana pseudostem - an abundant waste product of banana production - has considerable potential as a feedstock for the generation of biofuels and other high-value molecules. Acid and alkaline pretreatments in specific conditions can 
modify the banana pseudostem accessibility and provide high glucose yields by enzymatic hydrolysis, for fermentation processes.

\section{Acknowledgments}

The authors thank the Brazilian Innovation Agency (FINEP), the Brazilian Council for Research and Development (CNPq), and the National Institute of Metrology, Quality, and Technology (Prometro grant number 550105/2012-8) for financial support.

\section{References}

Adinugraha, M.P., Marseno, D.W., 2005. Synthesis and characterization of sodium carboxymethylcellulose from Cavendish banana pseudo stem (Musa cavendishii lambert). Carbohydr. Polym. 62, 164-169.

Benjamin, Y., Cheng, H., Görgens, J.F., 2013. Evaluation of bagasse from different varieties of sugarcane by diluteacid pretreatment and enzymatic hydrolysis. Ind. Crops Prod. 51, 7-18.

Brienzo, M., Siqueira, A.F., Milagres, A.M.F., 2009. Search for optimum conditions of sugarcane bagasse hemicellulose extraction. Biochem. Eng. J. 46, 199-204.

Brienzo, M., Ferreira, S., Vicentim, M.P., Souza, W., Sant'Anna, C., 2014. Comparison study on the biomass recalcitrance of different tissue fractions of sugarcane culm. Bioenergy Res. 7, 1454-1465.

Brienzo, M., Tyhoda, L., Benjamin, Y., Görgens, J., 2015. Relationship Between Physicochemical Properties and Enzymatic Hydrolysis of Sugarcane Bagasse Varieties for Bioethanol Production. C.

Brienzo, M., Abud, Y., Ferreira, S., Corrales, R.C.N.R., Ferreira-Leitão, V.S., De Souza, W., Sant'Anna, C., 2016. Characterization of anatomy, lignin distribution, and response to pretreatments of sugarcane culm node and internode. Ind. Crop Prod. 84, 305-313.

Brienzo, M., Fikizolo, S., Benjamin, Y., Tyhoda, L., Görgens, J., 2017. Influence of pretreatment severity on structural changes, lignin content and enzymatic hydrolysis of sugarcane bagasse samples. Renew. Energy 104, 271-280.

Cavalaglio, G., Gelosia, M., D’Antonio, S., Nicolini, A., Pisello, A.L., Barbanera, M., Cotana, F., 2016. Lignocellulosic ethanol production from the recovery of stranded driftwood residues. Energies 9, 634.

Chandra, R., Ewanick, S., Hsieh, C., Saddler, J.N., 2008. The characterization of pretreated lignocellulosic substrates prior to enzymatic hydrolysis, part 1: a modified Simons' staining technique. Biotechnol. Prog. 24, 1178-1185.

Chittibabu, S., Rajendran, K., Santhanmuthu, M., Saseetharan, M., 2011. Optimization of microwave assisted alkali pretreatment and enzymatic hydrolysis of Banana pseudostem for bioethanol production. Int. J. Environ. Sci. Technol. 67-71.

Cordeiro, N., Belgacem, M.N., Torres, I.C., Moura, J.C.V.P., 2004. Chemical composition and pulping of banana pseudostems. Ind. Crops Prod. 19, 147-154.

Corrales, R.C.N.R., Mendes, F.M.T., Perrone, C.C., Sant'Anna, C., de Souza, W., Abud, Y., Ferreira-Leitão, V., 2012. Structural evaluation of sugar cane bagasse steam pretreated in the presence of $\mathrm{CO} 2$ and SO2. Biotechnol. Biofuels 5, 36.
Fengel, D., Wegener, G., 1984. Wood: Chemistry, Ultrastructure, Reactions. Berlin, New York.

Guha, S.R.D., 1960. Kraft papers from banana stems. India Pulp Paper 15, 311-315.

Hu, Z., Wen, Z., 2008. Enhancing enzymatic digestibility of switchgrass by microwaveassisted alkali pretreatment. Biochem. Eng. J. 38, 369-378.

Idrees, M., Adnan, A., Malik, F., Qureshi, F.A., 2013. Enzymatic saccharification and lactic acid production from banana pseudostem through optimized pretreatment at lowest catalyst concentration. EXCLI J. 12, 269.

Junior, C.S., Milagres, A.M.F., Ferraz, A., Carvalho, W., 2013. The effects of lignin removal and drying on the porosity and enzymatic hydrolysis of sugarcane bagasse. Cellulose 20, 3165-3317.

Li, K., Fu, S., Zhan, H., Zhan, Y., Lucia, L., 2010. Analysis of the chemical composition and morphological structure of banana pseudostem. BioResources 5, 576-585.

Meng, X., Foston, M., Leisen, J., Demartini, J., Wyman, C.E., Ragauskas, A.J., 2013. Determination of porosity of lignocellulosic biomass before and after pretreatment by using Simons' stain and NMR techniques. Bioresour. Technol. 144, 467-476.

Monte, J.R., Brienzo, M., Milagres, A.M.F., 2010. Utilization of pineapple stem juice to enhance enzyme-hydrolytic efficiency for sugarcane bagasse after an optimized pretreatment with alkaline peroxide. Appl. Energy 88, 403-408.

Mooney, C.A., Mansfield, S.D., Touhy, M.G., Saddler, J.N., 1998. The effect of initial pore volume and lignin content on the enzymatic hydrolysis of softwoods. Bioresour. Technol. 64, 113-119.

Quintero, J.A., Montoya, M.I., Sánchez, O.J., Giraldo, O.H., Cardona, C.A., 2008. Fuel ethanol production from sugarcane and corn: comparative analysis for a Colombian case. Energy 33, 385-399.

Sant'Anna, C., Souza, W., Brienzo, M., 2014. The influence of the heterogeneity, physicochemical and structural properties on the recalcitrance and conversion of sugarcane bagasse. Sugarcane, Production, Consumption and Agricultural Management Systems. Webb, E. New York, Nova Science Publisehrs.

Siqueira, G., Milagres, A.M.F., Carvalho, W., Koch, G., Ferraz, A., 2011. Topochemical distribution of lignin and hydroxycinnamic acids in sugar-cane cell walls and its correlation with the enzymatic hydrolysis of polysaccharides. Biotechnol. Biofuel $4,7$.

Sluiter, A., Hames, B., Ruiz, R., Scarlata, C., Sluiter, J., Templeton, D., Crocker, D., 2010 Determination of Structural Carbohydrates 808 and Lignin in Biomass. Laboratory Analytical Procedure (LAP).

Souza, O., Federizzi, M., Coelho, B., Wagner, T.M., Wisbeck, E., 2010. Biodegradation of lignocellulosics residues generated in banana cultivation and its valorization for the production of biogas. Rev. Bras. Eng. Agríc. 14, 438-443.

Souza, O., Schulz, M.A., Fischer, G.A., Wagner, T.M., Sellin, N., 2012. Alternative energy from biomass: bioethanol from banana pulp and peels. Rev. Bras. Eng. Agríc. 16, 915-921.

Wuyts, N., De Waele, D., Swennen, R., 2006. Extraction and partial characterization of polyphenol oxidase from banana (Musa acuminata Grande naine) roots. Plant Physiol. Biochem. 44, 308-314.

Zhu, L., O’Dwyer, J.P., Chang, V.S., Granda, C.B., Holtzapple, M.T., 2008. Structural features affecting biomass enzymatic digestibility. Bioresour. Technol. 99, 3817-3828. 